\title{
Assessment of Heritability and Genetic Variabilty for Morphological and Yield Contributing Traits in Open Pollinated Maize Varieties
}

\author{
Shuja Ur Rehman Qureshi ${ }^{1}$, Mussaddiq Khan Khalil ${ }^{2, *}$ \\ ${ }^{1}$ Plant Breeding and Genetics, University of Agriculture Peshawar, KPK, Pakistan \\ ${ }^{2}$ Soil and Environmental Science, University of Agriculture Peshawar, KPK, Pakistan
}

Email address:

mussaddiqses@gmail.com (M. K. Khalil)

${ }^{*}$ Corresponding author

To cite this article:

Shuja Ur Rehman Qureshi, Mussaddiq Khan Khalil. Assessment of Heritability and Genetic Variabilty for Morphological and Yield Contributing Traits in Open Pollinated Maize Varieties. American Journal of BioScience. Vol. 7, No. 6, 2019, pp. 99-103.

doi: 10.11648/j.ajbio.20190706.13

Received: October 8, 2019; Accepted: November 25, 2019; Published: December 2, 2019

\begin{abstract}
The knowledge of heritability helps the plant breeder to understand the performance of an attribute under consideration in next generation. Fourteen genotypes including one local check were assessed at the experimental farm of The University of Agriculture, Peshawar during spring 2016. The experiment was laid out in randomized complete block design with three replications. Analysis of variance showed highly significant differences $(\mathrm{P} \leq 0.01)$ for days to anthesis, days to silking, plant height, ear height, cob length, kernel rows $\mathrm{cob}^{-1}$ and 100-kernel weight, whereas grain yield revealed nonsignificant differences ( $\mathrm{P}>0.05)$ among the genotypes evaluated. Genotypes, PSCV-9, PSCV-11, PSCV-13 and Azam as a check showed minimum days to anthesis (77.33), while minimum days to silking (79.33) were exhibited by Azam as a check. Genotype, PSCV-8 showed minimum plant height $(107.13 \mathrm{~cm})$ and ear height $(41.73 \mathrm{~cm})$, while maximum plant height $(147.33 \mathrm{~cm})$ and ear height $(70.86 \mathrm{~cm})$ was observed for PSCV-12. Genotype, PSCV-8 showed minimum ear length $(17.28$ $\mathrm{cm})$, while maximum ear length $(22.47 \mathrm{~cm})$ was observed for PSCV-4. Minimum number of kernel rows $\mathrm{cob}^{-1}(12.33)$ were observed for PSCV-8, while maximum number of kernel rows $\operatorname{cob}^{-1}$ (15.33) were observed for PSCV-4. Minimum 100-kernel weight (28 g) was observed for PSCV-5 and Azam as a check, while maximum 100-kernel weight (38 g) was observed for PSCV-3. Low to moderate broad sense heritability estimates were observed for all the traits except for days to anthesis and days to silking which showed high to moderate heritability estimates. The present study revealed considerable amount of diversity among open pollinated maize varieties which could be utilized for further improvement in maize breeding.
\end{abstract}

Keywords: Heritability, Genetic Variability, Yield Components, Maize

\section{Introduction}

Maize belongs to family of grasses (Poaceae) and ranks third in cereals [1]. It is a monoecious plant with staminate flowers on the terminal branched end of a tall erect stem (tassel) and pistillate flowers on axillary shoots [2]. In the beginning of floret development, staminate florets develop on the ear shoot and pistillate florets may develop on the tassel, but they usually remain rudimentary. Axillary shoots develop in acropetal succession during early stages of plant development [3]. Typical corn plant develops 20 to 21 total leaves, silks about 65 days after emergence, and matures around 100-125 days after emergence [4].

Maize is widely cultivated throughout the world and a greater weight of maize is produced each year than any other crop [1]. The USA produces $40 \%$ of the world's harvest; other top producing countries include China, Brazil, Mexico, Indonesia, India, France and Argentina [5]. In Pakistan, maize grain contributes $2.1 \%$ to the value added in agriculture and $0.4 \%$ to GDP. The area under maize cultivation in Pakistan was 1168.5 thousand hectares with the production of 4944.2 thousand tons. In Punjab, area under cultivation was 689.3 thousand hectares with the production of 4020.8 thousand tons, while in Khyber Pukhtunkhwa, area 
was 470.9 thousand hectares with the production of 914.8 thousand tons [6]. Peshawar, Kohat, Malakand, Hazara, and D. I Khan are chief maize growing regions in Khyber Pukhtunkhwa. The bulk (97\%) of the total production come from two major provinces, Khyber Pukhtunkhwa, accounting for $57 \%$ of the total area and $68 \%$ of total production. Punjab contributes $38 \%$ acreage with $30 \%$ of total maize grain production [6].

In spite of high yielding and easily cultivated crop than any other cereal, maize production in Pakistan is still low as compared to other important maize growing countries of the world. To increase maize yield, it is imperative for the maize breeders to develop maize varieties that are high yielding, widely adopted, early maturing, disease resistant, responsive to improved production practices and adjustable in the existing cropping pattern. Maize populations can be genetically improved by using several breeding methods like mass selection, modified ear-to-row selection, full sib selection, half sib selection, various methods of recurrent selection and hybridization. Evaluation of genotypes for grain yield and morphological traits is an important step towards the development of a variety. The main objectives of the present investigation were to, (i) estimate genetic variability and heritability for various morphological traits of open pollinated maize varieties, and to (ii) evaluate open pollinated maize varieties as a source of germplasm for use in future maize breeding programs.

\section{Material and Methods}

This study was conducted at the University of Agriculture, Peshawar in 2016. Breeding material was comprised of 14 maize varieties which were evaluated in randomized complete block design (RCBD) with three replications. Sowing was done in the second week of March, 2016. The maize varieties evaluated were PSCV-1, PSCV-2, PSCV-3, PSCV-4, PSCV-5, PSCV-6, PSCV-7, PSCV-8, PSCV-9, PSCV-10, PSCV-11, PSCV-12, and PSCV-13 while Azam was used as a check. Each plot was comprised of two rows with a row length of $5 \mathrm{~m}$, row to row distance of $75 \mathrm{~cm}$ and plant to plant distance of $25 \mathrm{~cm}$. Standard cultural practices were carried out throughout the growing season. Data were recorded on the following parameters:

\subsection{Data Recording}

Days to pollen shedding were recorded from date of planting till pollen shedding started on central branch of the tassel after dehiscence of anthers on $50 \%$ plants in a plot of a maize genotype. Days to silking were recorded when the silks emerged on the top most ear (primary ear) of at least $50 \%$ plants in a plot. Height of the plants was measured as the distance from ground level to the auricle of the flag leaf. Plant height data was taken on 10 randomly selected plants, and was then averaged. Ear height was measured as the distance from the soil to the node bearing the primary ear (uppermost). Data on 10 randomly selected plants were recorded and average ear height on per plot basis was calculated. Length of the 10 randomly chosen ears was measured to estimate average ear length. Grain rows of the 10 randomly selected ears were counted and average number of kernel rows per ear for each plot was determined. Hundred grains from the 10 randomly selected ears were weighed separately for each plot to determine average 100-grain weight in grams. The grain yield of each plot/genotype was calculated in $\mathrm{kg} / \mathrm{ha}$ after harvesting and adjusting fresh ear weight. Grain yield was calculated using the following relationship.

\subsection{Statistical Analysis}

Analysis of variance was used to determine significant difference of the genotypes for various parameters using the procedure of Jan et al. (2009) [7] for Randomized Complete Block Design. Also, the data were subjected to computer program "Statistix 10.1".

\section{Results and Discussion}

\subsection{Days to 50\% Anthesis}

Days to $50 \%$ anthesis is an important trait in determining maturity period of maize crop. Pollen shedding at right time and its perfect synchronization with silking will ensure high kernel filling and ultimately higher yield. Analysis of variance showed highly significant difference among maize genotypes for days to anthesis (Table 1). Mean values for days to anthesis ranged from 77.33 to 82.33 (Table 2). The minimum value 77.33 days for days to anthesis was recorded for genotype PSCV-9, PSCV-13 and Azam check, while maximum value of 82.33 days was recorded for genotype PSCV-5. Rahman et al. (2012) [8]; Ishaq et al. (2015) [9] also observed highly significant differences for this trait in the assessment of testcrosses of S1 lines for morphological and maturity characters of maize. Genotypic variance was 2.99, while phenotypic variance was 3.93. Broad sense heritability (h2BS) was recorded to be $76 \%$.

\subsection{Days to 50\% Silking}

Analysis of variance showed highly significant difference among maize genotypes for days to silking (Table 1). Mean values for days to silking ranged from 79.33 to 86 (Table 2). The minimum value for days to silking of 79.33 days was recorded for genotype Azam (check), while maximum value of 86 days was recorded for genotype PSCV-6. Rahman et al. (2012) [8] also found highly significant variation in the assessment of testcrosses of S1 lines for morphological and maturity characters of maize. Genetic variance was 2.42, while phenotypic variance was 4.2 . Broad sense heritability (h2BS) was recorded to be $57 \%$.

\subsection{Plant Height (cm)}

Plant height is an essential parameter and has a fundamental role in lodging that considerably affects maize production. In plant breeding programs, preference is given to plant height for 
increasing the yield and lodging resistance, therefore medium height is preferred for lodging control. Analysis of variance showed highly significant difference among the maize genotypes for plant height (Table 1). Mean values ranged from 107.13 to $147.33 \mathrm{~cm}$ (Table 3). The minimum value of 107.13 $\mathrm{cm}$ was recorded for genotype PSCV-8, while maximum value of $147.33 \mathrm{~cm}$ was recorded for genotype PSCV-12. Genetic variance was 68.12 , while phenotypic variance was 162.58 and broad sense heritability (h2BS) was recorded to be $41 \%$. The heritability was moderate which showed some level of environmental effect in breeding material under study. Rahman et al. (2012) [8]; Ishaq et al. (2015) [9] also reported highly significant differences and moderate heritability for this trait while studying testcrosses developed from maize variety Azam at CCRI.

\subsection{Ear Height (cm)}

The location of ear in maize is essential for lodging resistance. If the ear is located above the middle, the plant will be affected by lodging and if it is situated below the middle, it becomes vulnerable to rodents attack [10]. The placement of ear on height from soil level apply pressure on plant during maturity and grain filling time which could cause lodging and ultimately yield could be affected. So, the ear should be at the center and optimal position. Analysis of variance showed highly significant differences among maize genotypes for ear height (Table 1), Mean values ranged from 41.73 to $70.86 \mathrm{~cm}$ (Table 3). The minimum value of $41.73 \mathrm{~cm}$ was recorded for genotype PSCV-8, while maximum value of $70.86 \mathrm{~cm}$ was recorded for genotype PSCV-12. Genetic variance was recorded to be 40.67 , while phenotypic variance was 102.29 and broad sense heritability (h2BS) was recorded to be $39 \%$. The heritability was low to moderate which showed some level of environmental effect in breeding material under study. These results are similar with the findings of Rahman et al. (2012) [8] who reported significant differences and low (17\%) broad sense heritability for ear height.

\subsection{Ear Length (cm)}

Maize ear length is a primary yield component affecting the net grain yield of maize plant. Statistical analysis of the data regarding ear length revealed significant differences at $5 \%$ among the maize genotypes (Table 1). Mean values ranged from 17.28 to $22.47 \mathrm{~cm}$ (Table 4). The minimum value of $17.28 \mathrm{~cm}$ was recorded for genotype PSCV-8, while maximum value of $22.47 \mathrm{~cm}$ was recorded for genotype PSCV-4. Turi et al. (2007) [11]; Sesay et al. (2016) [12]; also obtained significant differences for ear length among the maize hybrids while studying topcross and three-way cross maize hybrids. Genetic variance was 0.78 , while phenotypic variance was 2.82. Broad sense heritability was recorded to be $27 \%$. The heritability was low to moderate which showed some level of environmental effect in breeding material under study.

\subsection{Kernel Rows Ear $^{-1}$}

Kernel rows ear ${ }^{-1}$ is an important yield parameter which can significantly contribute to the grain yield and ultimately total grain production. Data regarding kernel rows ear ${ }^{-1}$ showed significant differences at $5 \%$ among the maize genotypes (Table 1). Mean values ranged from 12.33 to 15.33 (Table 4). The minimum value of (12.33) was recorded for genotype PSCV-8, while maximum value of 15.33 was recorded for genotype PSCV-4. (Poudel and Poudel 2013) [16]; Sesay et al. (2016) [12] have observed highly significant differences among the hybrids for kernel rows per ear. Genetic variance $(\mathrm{Vg})$ was recorded as 0.47 and phenotypic variance $(\mathrm{Vp})$ was 1.59 while heritability was recorded to be $20 \%$. The heritability was low which showed some level of environmental effect in breeding material under study.

\subsection{0-Kernel Weight (g)}

Hundred-kernel weight along with the plant height and ear length is the major yield contributing factor and is important parameter for selection. Data pertaining to 100 kernel weight, revealed significant differences at 5\% among the maize genotypes (Table 1). Mean values ranged from 28 to $38 \mathrm{~g}$ (Table 4). The minimum value of $28 \mathrm{~g}$ was recorded for genotype PSCV-5 and Azam (check), while maximum value of $38 \mathrm{~g}$ was recorded for genotype PSCV-3. Highly significant differences were observed among the half sib families derived from Sarhad White variety of maize by Kaleem et al. (2013) [13]; Rahman et al. (2015) [14]. Genetic variance was 5.74, while phenotypic variance was 18.58. Broad sense heritability (h2BS) was recorded to be $30 \%$. The heritability was moderate which showed some level of environmental effect in breeding material under study.

\subsection{Grain Yield ( $\left.\mathrm{kg} \mathrm{ha}^{-1}\right)$}

Grain yield is the most important and a complex character with which a breeder works. It is a function of numerous biochemical and physiological processes that operates throughout the life cycle of crop plants. Analysis of variance showed non-significant differences among the maize genotypes (Table 1). Mean values ranged from 2580.25 to $5657.33 \mathrm{~kg} \mathrm{ha}^{-1}$ (Table 4). The minimum value of $2580.25 \mathrm{~kg}$ $\mathrm{ha}^{-1}$ was recorded for genotype PSCV-8, while maximum value of $5657.33 \mathrm{~kg} \mathrm{ha}^{-1}$ was recorded for PSCV-4. Similar result of non-significant differences in grain yield was also observed by (Poudel and Poudel, 2013) [16]; (Izzam, 2015) [15]. Genetic variance was 144905.53, while phenotypic variance $(\mathrm{Vp})$ was 1461659 . Broad sense heritability $\left(\mathrm{h}^{2}{ }_{\mathrm{BS}}\right)$ was recorded to be $10 \%$. The heritability was low which showed some level of environmental effect in breeding material under study. 
Table 1. Mean squares and Coefficient of variation for various parameters of OPV's evaluated at University of Agriculture, Peshawar in 2016.

\begin{tabular}{llll}
\hline TRAITS & Genotype Mean Squares & Error Mean Squares & Coefficient of Variation (\%) \\
\hline Days to anthesis & $9.93^{* *}$ & 0.94 & 1.21 \\
Days to silking & $9.06^{* *}$ & 1.78 & 1.59 \\
Plant height & $298.84^{* *}$ & 94.46 & 7.40 \\
Ear height & $183.63^{* *}$ & 61.62 & 14.80 \\
Ear length & $4.40^{*}$ & 2.04 & 7.34 \\
Kernel rows/cob & $2.54^{*}$ & 1.12 & 7.60 \\
100-Grain weight & $30.07^{*}$ & 12.84 & 11.05 \\
Grain yield & $1751470.64^{\text {ns }}$ & 1316754.04 & 26.79 \\
\hline
\end{tabular}

$\mathrm{NS}=$ non-significant

*,** significant at $5 \%$ and $1 \%$ levels of probability respectively.

Table 2. Mean values and ranges for days to anthesis, days to silking, plant height and ear height of 14 OPV's evaluated at University of Agriculture, Peshawar in 2016.

\begin{tabular}{lllll}
\hline GENOTYPES & Days to Anthesis & Days to Silking & Plant Height (cm) & Ear Height (cm) \\
\hline PSCV-1 & 81.66 & 84.66 & 143.20 & 49.60 \\
PSCV-2 & 80.33 & 83.33 & 128.46 & 50.60 \\
PSCV-3 & 81.33 & 84.00 & 138.40 & 49.20 \\
PSCV-4 & 80.66 & 84.33 & 125.73 & 56.60 \\
PSCV-5 & 82.33 & 84.66 & 135.93 & 61.40 \\
PSCV-6 & 81.33 & 84.66 & 126.73 & 46.86 \\
PSCV-7 & 78.33 & 83.33 & 136.46 & 53.60 \\
PSCV-8 & 80.66 & 81.00 & 107.13 & 41.73 \\
PSCV-9 & 77.33 & 82.33 & 132.13 & 58.06 \\
PSCV-10 & 80.33 & 83.66 & 138.00 & 59.80 \\
PSCV-11 & 77.66 & 82.66 & 124.26 & 47.80 \\
PSCV-12 & 81.00 & 79.33 & 147.33 & 70.86 \\
PSCV-13 & 77.33 & $79.33-86.00$ & 123.93 & 43.13 \\
Azam (check) & 77.33 & 129.13 & 53.20 \\
RANGE & $77.33-82.33$ & 2.22 & $107.13-147.33$ & $41.73-70.86$ \\
LSD (0.05) & 1.61 & 16.26 & 13.13 \\
\hline
\end{tabular}

Table 3. Mean values and ranges for ear height, kernel rows $\mathrm{cob}^{-1}, 100$-grain weight and grain yield of 14 OPV's evaluated at University of Agriculture, Peshawar in 2016.

\begin{tabular}{lllll}
\hline GENOTYPES & Ear Length $(\mathrm{cm})$ & Kernel rows cob $^{-1}$ & 100-grain weight (g) & ${\text { Grain yield }\left(\mathbf{k g ~ h a}^{-1}\right)}$ \\
\hline PSCV-1 & 20.02 & 14.88 & 29.33 & 4365.47 \\
PSCV-2 & 20.44 & 13.33 & 29.33 & 4111.43 \\
PSCV-3 & 13.93 & 15.35 & 38.00 & 4481.46 \\
PSCV-4 & 22.47 & 14.66 & 34.00 & 5657.33 \\
PSCV-5 & 19.34 & 12.66 & 28.00 & 3779.52 \\
PSCV-6 & 20.35 & 14.89 & 36.66 & 4003.26 \\
PSCV-7 & 12.33 & 35.33 & 5170.68 \\
PSCV-8 & 19.97 & 13.55 & 32.66 & 2580.25 \\
PSCV-9 & 17.28 & 14.00 & 34.66 & 5341.23 \\
PSCV-10 & 13.11 & 30.00 & 3963.33 \\
PSCV-11 & 18.86 & 13.00 & 33.33 & 3958.59 \\
PSCV-12 & 18.58 & 13.22 & 32.66 & 4556.86 \\
PSCV-13 & 18.42 & 14.33 & 32.00 & 3859.05 \\
Azam (check) & 19.37 & $12.33-15.33$ & 28.00 & 4127.35 \\
RANGE & 19.48 & 1.76 & $28.00-38.00$ & $2580.25-5657.33$ \\
LSD (0.05) & 18.78 & 5.99 & 1920.7 \\
\hline
\end{tabular}

Table 4. Genetic variance, phenotypic variance and broad sense heritability calculated for various parameters of OPV's evaluated during 2016.

\begin{tabular}{llll}
\hline TRAITS & Genetic variance & Phenotypic variance & Broad Sense Heritability \\
\hline Days to Anthesis & 2.99 & 3.93 & $76 \%$ \\
Days to silking & 2.42 & 4.20 & $57 \%$ \\
Plant height & 68.12 & 162.58 & $41 \%$ \\
Ear height & 40.67 & 102.29 & $39 \%$ \\
Ear length & 0.78 & 2.82 & $27 \%$ \\
Kernel row/ear & 0.47 & 1.59 & $20 \%$ \\
\hline
\end{tabular}




\begin{tabular}{llll}
\hline TRAITS & Genetic variance & Phenotypic variance & Broad Sense Heritability \\
\hline 100-kernel weight & 5.74 & 18.58 & $30 \%$ \\
Grain Yield & 144905.53 & 1461659 & $10 \%$ \\
\hline
\end{tabular}

\section{Conclusions}

Estimation of heritability for all the parameters was low to moderate which displayed comparatively high environmental influences on the trait's expression in the breeding material. The breeding material which had low heritability estimation could be evaluated in multiple-location zones. However, genotypes PSCV-9 and PSCV-13 took minimum days to anthesis and can be used for the development of early maturing genotypes. Analyzed data regarding plant and ear height showed highly significant difference among the populations. Plant height and ear height play important role in plant lodging. Therefore, maize breeders give special attention to these two traits and are interested in developing new populations having less vulnerability to lodging.

\section{References}

[1] Lance G. and B. Garren. 2014. "Origin, History and Uses of Corn”. Iowa State University, Department of Agronomy.

[2] Maruthi R. and J. Rani. 2015. Genetic variability, heritability and genetic advance estimates in maize (Zea mays L.) inbred line. Journal of Applied and Natural Science 7 (1): 149-154.

[3] Farnia, A. and M. Mansouri. 2015. Study on morphological characteristics of maize (Zea mays L.) cultivars under different plant densities. Indian Journal of Natural Sci. 5: 0976-0997.

[4] Smith J., Smith O. and Lamkey K. 2005. Maize breeding. Iowa State University, Department of Agronomy. Maydica 50: 185-192.

[5] FAO (Food and Agriculture Organization). 2006. FAO Quarterly bullentin of statistics. Food and Agriculture Organization of the United Nations, Rome Italy, 10: 5-6.

[6] MNFSR. 2014. Agriculture statistics of Pakistan. Ministry of National Food Security and Research, Islamabad, Pakistan.

[7] Jan, M. T., P. Shah, P. A. Hollington, M. J. Khan and Q.
Sohail. 2009. Agriculture Research: Design and Analysis. Dept. of Agronomy, KPK Agric. Uni. Peshawar, Pakistan.

[8] Rahman H., A. Nazir, M. Faizan, A. Shahaab, R. Ali and A. Abbas. 2012. Evaluation of half -sib families derived from maize variety Sarhad white for grain yield and agronomic traits. Middle-East Journal of Medicinal Plants Research 1 (4): 80-85.

[9] Ishaq M., H. Rahman, G. Hassan, M. Iqbal, I. Khalil, Khan A., Rafiullah and J. Hussain. 2015. Genetic potential, variability and heritability of various morphological and yield traits among maize synthetic. Electronic Journal of Biology 11 (4): 187-191.

[10] Bello O., S. A. Ige, Azeez M., Afolabi M., Abdulmaliq S., Mahamood J. 2012. Heritability and genetic advance for grain yield and its component characters in maize (Zea Mays L.). International Journal of Plant Research 2 (5): 138-145.

[11] Turi N., Shah S., Ali S., H. Rahman, T. Ali and M. Sajjad. 2007. Genetic variability for yield parameters in maize (Zea Mays L.) genotypes. Journal of Agricultural and Biological Science 2: 4-5.

[12] Sesay S,. Ojo D., Ariyo J. and Meseka S. 2016. Genetic variability, heritability and genetic advance studies in topcross and three-way cross maize (Zea mays L.) hybrid. Maydica, 61: $1-7$.

[13] Kaleem U., H. Rahman, M. Noor, M. Rehman, M. Iqbal and Sanaullah. 2013. Heritability estimates and yield performance of half sib families derived from maize variety Sarhad white. Sarhad J. Agric. 29 (1): 29-32.

[14] Rahman H., Habibullha, L. Shah, A. Ali. 2015. Estimates of heritability and genetic advance for morphological traits improvement in maize (Zea mays L.). Acad. J. Agric. Res. 3 (1): 009-014.

[15] Izzam A. 2015. Evaluation of maize hybrids for grain yield and morphological traits. M. Sc thesis submitted to the Department of Plant Breeding and Genetics, The University of Agriculture Peshawar.

[16] Poudel M. and H. Poudel. 2013. Genetic variability, heritability and genetic advance of yield attributing traits in winter maize. Int. J. Grad. Res. Rev. 2 (1): 9-12. 